\title{
Primer Retroperitoneal Kist Hidatik
}

\author{
Primary Retroperitoneal Hydatid Cyst
}

\author{
Servet Tali, Ali Aksuํ, Pınar Gündoğan Bozdağ², Ahmet Bozdağ ${ }^{1}$ \\ ${ }^{1}$ Harput Devlet Hastanesi, Genel Cerrahi Kliniği, Elazığ, Türkiye \\ Elazığ Eğitim ve Araştırma Hastanesi, Radyoloji Kliniği, Elazığ, Türkiye
}

Öz

Kist hidatik hastalığı Echinococcus granulosus paraziti tarafından oluşturulan bir hastalıktır. Hidatik kist en sık karaciğer ve akciğerde yerleşmektedir. Hidatik kist retroperitonda cerrahi sonrası ekim yoluyla sekonder olarak görülebilir. Fakat primer retroperitoneal yerleşimli kist hidatik nadir görülür. Atmış üç yaşında kadın hasta sırt ağrısı ve karında şişkinlik şikayetleri ile hastanemize başvurdu. Karın ultrasonografi ve bilgisayarlı tomografide sol böbrek posteriorunda, paravertebral alanda retroperitoneal yerleşimli yaklaşık $15 \times 10 \mathrm{~cm}$ boyutlarında septalıkistik lezyon izlendi. Operasyonda retroperitoneal yerleşimli, inferiordarenal arter ve vene, süperiorda ise dalağa invaze kiste parsiyel eksizyon yapıldı ve bir adet dren ile kist poşunun drenajı sağlandı. Dren ameliyat sonrası 5. gün çıkartıldı. Histopatolojik tanısı hidatik kist olarak rapor edildi. Hidatik kist ülkemizde endemik bir hastalık olup atipik yerleşimleri de mevcuttur, retroperitoneal lezyonların ayıııı tanısında akılda bulunmalıdır. (Turkiye Parazitol Derg 2015; 39: 241-3)

Anahtar Kelimeler: Kist hidatik hastalığı, retroperitoneal hidatik kist, retroperiton

Geliş Tarihi: 14.10 .2014

Kabul Tarihi: 09.04.2015

\section{ABSTRACT}

Hydatid disease is a parasitosis which is created by Echinococcus granulosus. Hydatid cysts most of ten settled in the liver and lungs. Hydatid cyst is rarely seen in retroperitoneal. Sixty-three year-old female patient was admitted to our hospital with complaints of abdominal distention and with back pain in the Abdominal ultrasonography and computed tomography images, on the posterior of the left kidney, in paravertebral area approximately $15 \times 10 \mathrm{~cm}$ in size septal cystic lesion was observed retroperitoneally. At laparotomy, partial excision of the retroperitoneal cyst was performed and drainage of the cyst pouch was provided by suction drain. Suction drain was removed 5 days after surgery. Histopathological diagnos is was reported as hydatid cyst. Hydatid disease is a endemic disease in our country and it should be known that has a typical placements. (Turkiye Parazitol Derg 2015; 39: 241-3)

Keywords: Hydatid disease, retroperitoneal hydatid cyst, retroperiton

Received: 14.10.2014

Accepted: 09.04.2015

\section{Giriş}

Hidatik kist hastalığı, E.granulosus helmintinin neden olduğu paraziter bir infeksiyonudur. Genellikle primer olarak karaciğer (\%50-70) ve akciğerde (\%11-17) enfeksiyona neden olmasına rağmen vücudun her yerinde bulunabilirler $(1,2)$.

Retroperitoneal hidatik kist genellikle spontan, travma veya

Bu çalışma 35. Ulusal Radyoloji Kongresi' nde sunulmuştur, $11-16$ Kasım 2014, Antalya, Türkiye.

This study was presented in the 35th National Radiology Congress, 11-16 November 2014, Antalya, Turkey.

Yazışma Adresi / Address for Correspondence: Dr. Servet Tali. E.posta: drstali76@hotmail.com DOI: $10.5152 /$ tpd.2015.3905

CTelif hakkı 2015 Türkiye Parazitoloji Derneği - Makale metnine www.tparazitolderg.org web sayfasından ulaşılabilir. CCopyright 2015 Turkish Society for Parasitology - Available online at www.tparazitolderg.org 
diğer organların hidatik kist cerrahisi sırasında ekilme sonucu oluşabilir. Primer retroperitoneal hidatik kist son derece nadirdir (3). Bu yazıda, primer bir odağı olmayan atipik yerleşimli bir hidatik kist olgusu sunulmuştur.

\section{OLGU SUNUMU}

Sol üst kadranda şişkinlik ve sol sırt bölgesinde ağrı şikayetleri ile 63 yaşında bayan hasta polikliniğimize başvurdu. Hastanın fizik muayenesinde sol üst kadranda yaklaşık $10 \mathrm{~cm}$ boyutunda yumuşak kıvamlı bir kitle palpe edildi. Hastanın rutin biyokimyasal tetkiklerinde patolojik bulgu tespit edilmedi. Hastanın serolojik inceleme sonucu negatif idi. Hastaya batın ultrasonografisi yapıldı ve karaciğer sol lop komşuluğunda $15 \mathrm{~cm}$ çapında kist hidatiği düşündüren kitle lezyonu tarif edilmekteydi. Hastaya karın tomografisi (BT) ve akciğer grafisi çekildi. Akciğer grafisinde patoloji görülmedi. Karın $\mathrm{BT}^{\prime}$ de dalak ile sol böbrek arasında yaklaşık $15 \times 10 \mathrm{~cm}$ çapında, dalak ve sol böbrek ile arasında sınırı net ayırt edilemeyen kist hidatik olarak düşünülen lezyon görüldü (Resim 1-3). Hasta operasyona hazırlandı ve opere edildi. Eksplorasyonda dalak ile böbrek arasında yaklaşık 15 cm'lik kistik kitle görüldü. Omentum majör açıldı. Splenik flexura düşürüldü. Kitlenin inferiorda renal artere, vene ve sol böbrek üst polüne invaze olduğu görüldü. Kitle süperiorda dalak inferionunu invaze ederek posteriorda vertebraya kadar uzanıyordu. Kistin renal arter, ven ve sol böbreğe invaze olmasından dolayı total eksizyon yapılamadı. Daha sonra \%20 salin kist içerisine verildi ardından parsiyel kist eksizyonu yapıldı. Bir adet dren ile kist poşunun dışarı drenajı sağlandı. Dren ameliyat sonrası 5. gün çıkartıldı. Histopatolojik tanısı hidatik kist olarak rapor edildi. Postoperatif dönemde hastaya albendazol tedavisi verildi. Hastanın 6. ayda yapılan kontrol karın tomografisinde operasyon alanında nüks görülmedi ve normal idi. Hastaya bu bölgede görülen kist hidatik hastalığının nadir

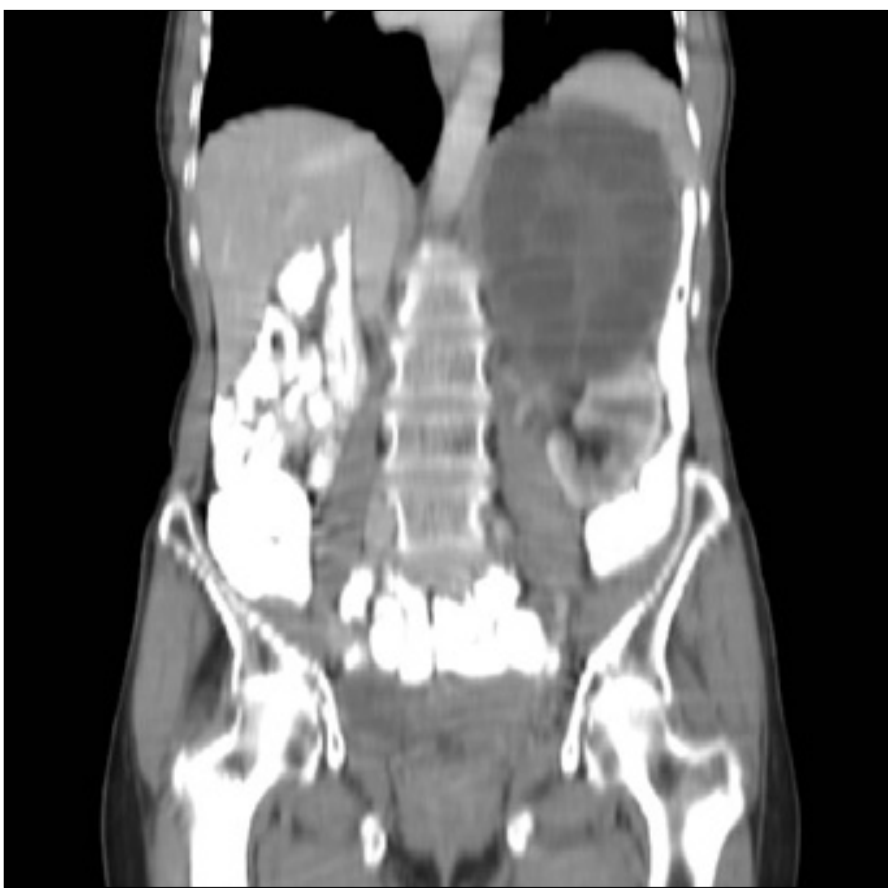

Resim 1. Iv ve oral kontrastlı BT'de koronal kesitte lezyon görünümü görüldüğü ve bilgilerinin bilimsel amaçlı yayınlanmak üzere kullanılacağı ifade edilerek yazılı ve sözlü onayı alınmıştır.

\section{TARTIŞMA}

Kist hidatik hastalığı E.granulosus helmintinin etken olduğu infeksiyonudur. Hidatik kist özellikle Asya, Akdeniz, Güney Amerika ve Afrika ülkelerinde endemik olarak görülmektedir ve hayvancılıkla uğraşılan, sahipsiz köpeklerin olduğu bölgelerde hastalığın görülme sıklığı artmaktadır (4). Türkiye kist hidatik

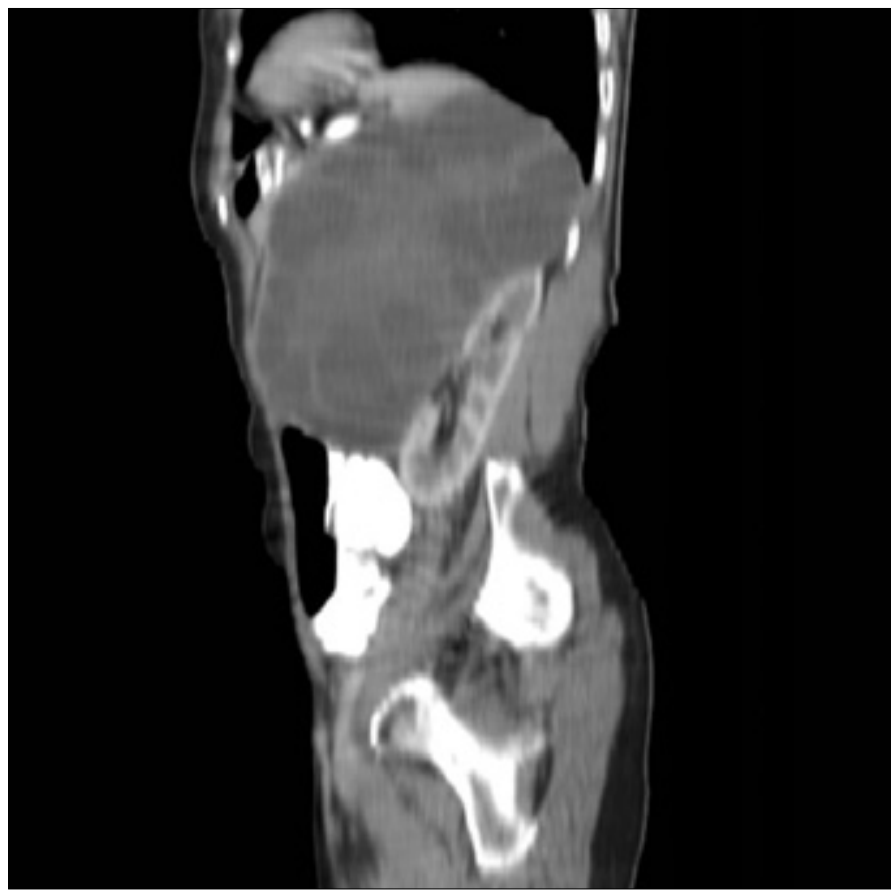

Resim 2. İ ve oral kontrastlı BT'de sagittal kesitte batın sol üst kadranda dalak, sol böbrek ve barsak anslarını deplase eden septalı kistik lezyon

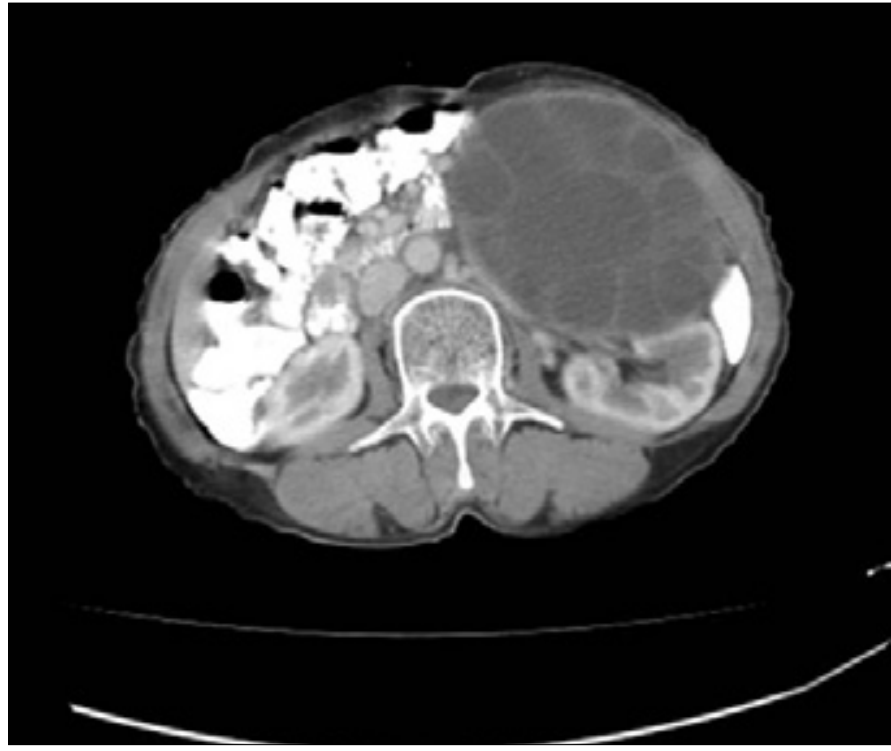

Resim 3. Iv ve oral kontrastlı aksiyel BT 'de batın sol kadranda sol böbrek, barsak ansları vasküler yapıları deplase eden septalı kistik lezyon 
olgularının çok sık olarak görüldüğü ülkelerden biridir ve sıklık olarak 1/2000 oranı bildirilmiştir (5).

E.granulosus'un esas konağı olan köpeklerin dışkısı ile atılan yumurtalar hem çiftlik hayvanları hem de insanlardaki enfeksiyonların asıl kaynağıdır. E. granulosus'un yaşam döngüsü esas olarak koyun ve sığır gibi çiftlik hayvanları ile köpekler arasında sürer. Ancak insanlar da ara konak olarak döngüde yer alır (1).

Literatürde karaciğere (\%50-70), akciğere (\%11-17), yumuşak dokulara $(\% 2,4-5,3)$, kalbe $(\% 0,5-3)$, perikarda $(\% 5)$, kas ve subkutan dokulara $(\% 0,5-4,7)$ yerleşim bildirilmiştir. Primer retropertoneal hidatik kist son derece nadirdir. Retroperitoneal hidatik kist genellikle diğer organların hidatik kist cerrahisi sırasında ekilme yoluyla veya spontan ya da travma ile rüptür sonucu oluşabilir (3). Yapılan tetkikler sonucunda hastamızda retroperitoneal hidatik kist dışında odak yoktu. Bu nedenle primer retroperitoneal hidatik kist olarak değerlendirildi.

Hidatik kist olguların çoğunluğu asemptomatik olmakla beraber semptomlar ise yerleştiği lokalizasyona ve kistin büyüklüğüne bağlıdır. Retroperitoneal yerleşimli hidatik kistte sıklıkla yan ağrısı ve sırt ağrısı görülebilir (6). Bizim hastamızda bir yıldır olan sol yan ağrısı ve karında şişkinlik şikayetleri mevcuttu. Tetkikleri sırasında retroperitoneal kist saptandı. Retroperitoneal hidatik kistin ayırıcı tanısında yumuşak doku tümörleri, kistik lenfanjiomlar, retroperitoneal abse, psödokist ve embriyonel kistler düşünülmelidir (7). Olgumuzda tespit edilen lezyon radyolojik olarak hidatik kist olarak yorumlandı. Ameliyat öncesi tanıda, klinik öykü, radyoloji ve serolojik test sonuçları yardımcı olabilir. Kesin tanı cerrahi ve histopatolojik inceleme ile konulur. İdeal tedavi seçeneği karın içine bulaşmayı önleyerek kistin eksizyonu ve sonrasında albendazol kullanılmasıdır. Invazyon ya da başka sebeplerle eksizyonu mümkün olmayan vakalarda parsiyel eksizyonva drenajda yapılabilinecek bir seçenektir $(8,9)$.

\section{SONUÇ}

Sonuç olarak ülkemiz kist hidatik hastalığı açısından endemik bir bölge olması nedeniyle, bu tür atipik yerleşimlere karaciğer dışında pek çok farklı anatomik bölgede rastlanabilir. Retroperitoneal kist hidatik nadir görülmesine rağmen, özellikle endemik bölgelerde retroperitoneal kitlelerin ayırıcı tanısında düşünülmesi gerektiğini vurgulamak isteriz.

Hasta Onamı: Yazılı hasta onamı hastadan alınmıştır.

Hakem Değerlendirmesi: Dış Bağımsız.
Yazar Katkıları: Fikir - S.T., A.A.; Tasarım - A.B., S.T.; Denetleme - A.B. Kaynaklar - S.T.; Malzemeler - P.G.B.; Veri Toplanması ve/veya işlemesi S.T., P.G.B.; Analiz ve/veya Yorum - A.B., A.A.; Literatür taraması - S.T., A.B.; Yazıyı Yazan - S.T.; Eleştirel İnceleme - A.B.

Çıkar Çatışması: Yazarların herhangi bir çıkar çatışması söz konusu değildir.

Finansal Destek: Bu makalede katkısı bulunan yazarlar herhangi bir finansal destek almamıştır.

Informed Consent: Written informed consent was obtained from the patient.

Peer-review: Externally peer-reviewed.

Author Contributions: Consept - S.T., A.A.; Design - A.B., S.T.; Supervision - A.B.; Funding - S.T.; Materials - P.G.B.; Data Collection and/ orProcessing - S.T., P.G.B.; Analysis and/or Interpretation - A.B., A.A.; LiteratureReview - S.T., A.B.; Writer - S.T.; Critical Review - A.B.

Conflict of Interest: No conflict of interest was declared by the authors.

Financial Disclosure: The authors declared that this study has received no financial support.

\section{KAYNAKLAR}

1. Bansal C, Lal N, Jain RC, Srivastava AN, Fatima U. Primary hydatid cyst in the soft tissue of the face: an exceptional occurrence. Indian J Dermatol 2011; 56: 768-70. [CrossRef]

2. Tekin M, Osma U, Yaldiz M, Topcu I. Preauricular hydatid cyst: an unusual location for echinoccosis. Eur Arch Otorhinolaryngol 2004; 261: 87-9. [CrossRef]

3. Gündeş E, Küçükkartallar T, Çakır M. Primary Retroperitoneal Hydatid Cyst. Turkiye Parazitol Derg 2014; 38: 68-70. [CrossRef]

4. Gürbüz B, Baysal H, Baysal B, Yalman H, Yiğitbaşı MR. Isolated Gluteal Hydatid Cyst. Turkiye Parazitol Derg 2014; 38: 51-4. [CrossRef]

5. Özlen B, Özdemir L, Yörük Y, Altıay G, Tabakoğlu E, Hatipoğlu O. A Case of Ruptured Hydatid Cyst With Upper Lobe Localization That Imitated Active Lung Tuberculosis. Balkan Med J 2007; 24: 146-9.

6. Markell EK, Voge M, John DT. The cestodes. Markell EK, Voge M, John DT, editors. Medical parasitology. Seventh edition. Philadelphia: WB Saunders; 1992. p. 226-60.

7. Engin G, Acunas B, Rozanes I, Acunaş G. Hydatid disease with unusual localization. Eur Radiol 2000; 10: 1904-12. [CrossRef]

8. Hatipoglu AR, Coşkun I, Karakaya K, Ibis C. Retroperitoneal localization of hydatid cyst disease. Hepatogastroenterology 2001; 48: 1037-9.

9. Balık AA, Çelebi F, Başoğlu M, Ören D, Yıldırgan I, Atamanalp SS. Intra-abdominal extrahepatic echinococcosis. Surg Today 2001; 31: 881-4.[CrossRef] 